\title{
Relevance of Combined Electron and Photon Beams in Radiotherapy of Head and Neck Cancers in the Era of Intensity-Modulated Radiotherapy
}

\author{
Vinod Pandey ${ }^{1}$ \\ K.C. Pandey ${ }^{1}$ \\ N.K. Pant ${ }^{1}$ \\ ${ }^{1}$ Department of Radiotherapy, Swami Ram Cancer Hospital \& \\ Research Institute, Haldwani, Uttarakhand, India \\ 2Department of Physics, Govt. P.G. College, Berinag, \\ Uttarakhand, India
}

\author{
Address for correspondence K.C. Pandey, MD, Department \\ of Radiotherapy, Swami Ram Cancer Hospital \& Research \\ Institute, Rampur Road, Haldwani 263139, Uttarakhand, India \\ (e-mail: drkcp89@gmail.com).
}

Asian J Oncol 2021;7:114-117.

\begin{abstract}
Keywords

- electron and photon beam

$-2 \mathrm{DRT}$

- IMRT

- survey

Introduction External beam radiotherapy (EBRT) for head and neck (H\&N) cancers continues to be delivered using varied technologies, ranging from the old two-dimensional conventional radiotherapy (2DRT) techniques to the modern three-dimensional conformal radiotherapy (3DCRT), intensity-modulated radiotherapy (IMRT), and volumetric modulated arc therapy (VMAT) in different centers in India. Due to limitations of spinal cord tolerance, electron and photon beams are combined in 2DRT and 3DCRT techniques for treating nodal volume of the H\&N cases. However, many centers having modern technology practice IMRT/VMAT in place of electron beams. The purpose of this study is to analyze the role of combined electron and photon beams in radiotherapy of $\mathrm{H} \& \mathrm{~N}$ cancers and its relevance in the modern era of IMRT/VMAT.

Materials and Methods Data were collected through a survey conducted on cancer centers in India where radiotherapy is being given by 2DRT, 3DCRT, and IMR/VMAT for the treatment of head and neck cancers.

Results The mean percentage of $\mathrm{H} \& \mathrm{~N}(\mathrm{H} \& \mathrm{~N})$ cases among all cases were $39.2 \%$ (standard deviation [SD]: 14.22), out of which $16.63 \%$ (SD: 20.83) were treated with a combination of photon and electron beams and $49.73 \%$ (SD: 37.41 ) were treated with IMRT/ VMAT. The average percentage of H\&N cases of government institutes was $38.39 \%$ (SD: 14.11 ) and that of private institutes was $40.14 \%$ (SD: 14.11). Patients treated with photon and electron combination and IMRT/VMAT were $22.19 \%$ (SD: 11.24) and 24.05\% (SD: 23.99), respectively, in government institutes, and 10.29\% (SD: 11.24) and $79.09 \%$ (SD: 26.75 ) in private institutes.

Conclusion As per this study, we conclude that despite the availability of IMRT/VMAT, a combination of electron and photon beams is still relevant in India. Since a large proportion of the patients are still treated with the electron and photon combination, it is imperative that further studies on field-junction dosimetry should be conducted to ensure accurate dose delivery.
\end{abstract}

published online November 29, 2020
DOI https://doi.org/ $10.1055 / \mathrm{s}-0040-1718636$ ISSN 2454-6798. (c) 2020. Spring Hope Cancer Foundation \& Young Oncologist Group of Asia.

This is an open access article published by Thieme under the terms of the Creative Commons Attribution-NonDerivative-NonCommercial-License, permitting copying and reproduction so long as the original work is given appropriate credit. Contents may not be used for commercial purposes, or adapted, remixed, transformed or built upon. (https://creativecommons.org/licenses/by-nc-nd/4.0/) Thieme Medical and Scientific Publishers Pvt. Ltd., A-12, 2nd Floor, Sector 2, Noida-201301 UP, India 


\section{Introduction}

Radiotherapy (RT) is one of the most important treatment modalities in the treatment of head and neck (H\&N) cancers. Till about two decades ago, a majority of RT centers world over used to deliver RT by two-dimensional conventional RT (2DRT) and by three-dimensional conformal radiotherapy RT (3DCRT) using linear accelerators (LINACs) and telecobalt machines. RT technology and treatment modalities have improved remarkably in the past two decades. Newer advances such as intensity-modulated RT (IMRT) and volumetric modulated arc RT (VMAT) have replaced the older treatment techniques to a large extent. ${ }^{1}$ However, telecobalt machines are still in use in India in many government and private institutes. ${ }^{2}$

LINAC is considered to be superior to telecobalt units due to several reasons, but one of the most important reasons is that LINAC is capable of generating electron beams of different energies, which are useful in treating the nodal volume of the primary tumors, especially near the spinal cord in some of the H\&N cancers. Radical RT with or without concurrent chemotherapy is the mainstay of treatment for a large majority of H\&N squamous cell carcinomas (HNSCCs). In countries such as India, with high population and chronic alcohol/tobacco use, H\&N cancers are an important clinical issue. ${ }^{3,4} \mathrm{~A}$ curative approach requires the delivery of up to 70 to $72 \mathrm{~Gy}$ of radiation dose, but this dose exceeds the spinal cord tolerance dose, which is 45 to $48.5 \mathrm{~Gy}$. ${ }^{3}$ Since many $\mathrm{H} \& \mathrm{~N}$ cancer patients have involvement of posterior neck nodes (level 4 nodes), ${ }^{5-8}$ it is not possible to deliver a curative dose to neck nodes with conventional RT without exceeding the spinal cord tolerance dose. The common practice is to deliver up to 44 to $46 \mathrm{~Gy}$ to the whole target including posterior neck nodes using photon beams followed by coned down photon beam to exclude the spinal cord. The boost dose to the posterior neck nodes is then delivered with electron beams. ${ }^{6-8}$ IMRT is another alternative. In the developed countries, most of the HNSCCs are treated with IMRT, and this negates the need for using electron field boost for the posterior neck nodes. However, in the Indian scenario, though IMRT is used at many centers, ${ }^{9}$ many other centers are still practicing 2DRT and 3DCRT in India. To know the current status of 2DRT and 3DCRT, a survey became imperative to ascertain the proportion of the patients treated with IMRT as compared with 2DRT/3DCRT plus electron boost. The purpose of this study is to assess the relevance of electron and photon beam in RT of H\&N cancers in the IMRT era in India by conducting a survey of cancer institutes.

\section{Materials and Methods}

We selected 40 cancer institute of India from different regions of the country. Data were collected through e-mails by sending the questionnaire and telephonic conversations with many physicists and radiation oncologists of India. Out of 40, we got the response from 30 institutes, out of which 16 were government and 14 were private cancers institutes in India having the facility of conformal RT (CRT)/3DCRT along with IMRT/VMAT. Data were collected, tabulated, and analyzed in MS Excel. The following three questions were asked during the survey:

1. What is the percentage of $\mathrm{H} \& \mathrm{~N}$ cancer cases for RT?

2. What is the percentage of $H \& N$ cases treated by a combination of photon and electron beam in CRT?

3. What is the percentage of cases treated by IMRT/VMAT?

\section{Results}

The results of the analysis are tabulated in -Tables 1-3. - Tables 1 and $\mathbf{2}$ show the percentage variation of H\&N cases, $\mathrm{H} \& \mathrm{~N}$ cases treated with a combination of photon and electron beam, and percentage of cases treated with IMRT in 16 government institutes and 14 private institutes, respectively.

- Table 3 shows that the mean percentage of H\&N cases among all cases was $39.2 \%$ (standard deviation [SD]: 14.22), out of which $16.63 \%$ (SD: 20.83) were treated with a combination of photon and electron beams and $49.73 \%$ (SD: 37.41 ) were treated with IMRT/VMAT. The average percentage of H\&N cases of government institutes was 38.39\% (SD: 14.11) and that of private institutes was $40.14 \%$ (SD: 14.11). Patient treated with photon and electron combination and IMRT/

Table 1 Percentage data of government institutions of H\&N cases treated with a combination of photon and electron beam and IMRT

\begin{tabular}{|c|c|c|c|}
\hline S. no. & $\begin{array}{l}\text { Percentage } \\
\text { of } \mathrm{H} \& \mathrm{~N} \\
\text { cases }\end{array}$ & $\begin{array}{l}\text { Percentage of } \\
\text { cases treated by } \\
\text { a combination } \\
\text { of photon and } \\
\text { electron beams }\end{array}$ & $\begin{array}{l}\text { Percentage of } \\
\text { cases treated } \\
\text { by IMRT }\end{array}$ \\
\hline 1 & 26 & 15 & 20 \\
\hline 2 & 40 & 1 & 30 \\
\hline 3 & 50 & 10 & 10 \\
\hline 4 & 30 & 5 & 12 \\
\hline 5 & 25 & 20 & 20 \\
\hline 6 & 60 & 15 & 5 \\
\hline 7 & 20 & 0 & 60 \\
\hline 8 & 59 & 40 & 8 \\
\hline 9 & 28 & 12 & 15 \\
\hline 10 & 60 & 25 & 10 \\
\hline 11 & 16 & 42 & 4.6 \\
\hline 12 & 35 & 10 & 10 \\
\hline 13 & 55 & 5 & 80 \\
\hline 14 & 45 & 20 & 70 \\
\hline 15 & 30.2 & 80 & 20 \\
\hline 16 & 35 & 10 & 10 \\
\hline Mean & 38.39 & 19.38 & 24.04 \\
\hline SD & 14.73 & 20.21 & 23.99 \\
\hline
\end{tabular}

Abbreviations: H\&N, head and neck; IMRT, intensity-modulated radiotherapy; SD, standard deviation. 
VMAT were 22.19\% (SD: 11.24 ) and 24.05\% (SD: 23.99), respectively, in government institutes, and $10.29 \%$ (SD: 11.24) and 79.09\% (SD: 26.75) in private institutes.

\section{Discussion}

From the extensive literature survey on the subject, we believe that this is the first survey of its kind on assessing relevance of the practice of 2DRT with electron boost as compared with IMRT/VAMT in H\&N cases in India. We observed that IMRT was more prevalent among private institutes. A majority of clinicians believed that IMRT is a better option as compared with 2DRT. Gupta et $\mathrm{al}^{10}$ reported that there was consistent evidence that IMRT significantly

Table 2 Percentage data of private institutes of H\&N cases treated with a combination of photon and electron beam and IMRT/VMAT

\begin{tabular}{|c|c|c|c|}
\hline S. no. & $\begin{array}{l}\text { Percentage of } \\
\text { H\&N cases }\end{array}$ & $\begin{array}{l}\text { Percentage } \\
\text { of cases } \\
\text { treated by a } \\
\text { combination } \\
\text { of photon and } \\
\text { electron beams }\end{array}$ & $\begin{array}{l}\text { Percentage of } \\
\text { cases treated } \\
\text { by IMRT/ } \\
\text { VMAT }\end{array}$ \\
\hline 1 & 60 & 12 & 70 \\
\hline 2 & 60 & 1 & 99 \\
\hline 3 & 55 & 12 & 5 \\
\hline 4 & 40 & 5 & 95 \\
\hline 5 & 37 & 5 & 95 \\
\hline 6 & 36 & 30 & 70 \\
\hline 7 & 30 & 30 & 70 \\
\hline 8 & 16 & 1 & 99 \\
\hline 9 & 56 & 0 & 100 \\
\hline 10 & 35 & 5 & 95 \\
\hline 11 & 30 & 5 & 95 \\
\hline 12 & 52 & 5 & 95 \\
\hline 13 & 24 & 30 & 70 \\
\hline 14 & 31 & 3 & 48.3 \\
\hline Mean & 40.14 & 10.29 & 79.09 \\
\hline SD & 14.11 & 11.24 & 26.75 \\
\hline
\end{tabular}

Abbreviations: H\&N, head and neck; IMRT, intensity-modulated radiotherapy; SD, standard deviation; VMAT, volumetric modulated arc therapy. reduced the risk of moderate, severe, acute and late xerostomia compared with 2D/3D RT in the curative-intent radiotherapeutic management of HNSCCs. However, the quality of evidence regarding the superiority of IMRT over conventional techniques for disease-related end points was rather low due to various reasons. Mahantshetty et al have reported in 2018 that IMRT should be used judiciously as there was a greater chance of missing the target volume due to uncertainties in target volume definition by the clinician along with random and systematic errors, which might lead to poor control considering a clear dose-response relationship in HNSCCs. ${ }^{5}$ They have cautioned that unless a center and clinician meet the standards to practice IMRT, it was better to treat patients with 2DRT instead of IMRT. Nelms et al have reported in variation in contouring of organ at risk volume in IMRT. ${ }^{11}$ IMRT treatment also requires a rigorous quality assurance program for getting the desired results. ${ }^{12}$ The aforementioned facts could be one of the main reasons behind lesser adoption of IMRT in government-run $\mathrm{RT}$ centers as compared with private institutes in India.

In the year 2005, there were 265 telecobalt machines and 75 conventional LINACs in use for delivering 2DRT and 3DCRT in India. ${ }^{2}$ In 2018, there were 347 RT centers in the country as per the International Atomic Energy Agency (IAEA) Directory of Radiotherapy Centres report. ${ }^{13,14}$ These RT centers have a total of 347 telecobalt and telecesium machines (delivering 2DRT) and 235 LINACs (delivering all three treatment modalities) as per Chauhan et al. ${ }^{13,14}$ This indicates that there was a $30.9 \%$ increase in the number of telecobalt machines from 2005 to 2018.

Ravichandran and Jayarajan et al ${ }^{15,16}$ explained the reasons for using telecobalt units in the present era of IMRT. A telecobalt unit is equivalent to a low-energy LINAC of approximately $4 \mathrm{MV}$ photon beam. In addition, minimal infrastructural requirements in terms of less power consumption, beam stability, and low maintenance cost of telecobalt machines uninterrupted treatments to patients especially in the rural setup where frequency of power fluctuations and failure rate are quite high. Hence, several $\mathrm{H} \& \mathrm{~N}$ cancer patients may have to be referred for nodal irradiation by using electron beam.

As per the World Bank and IAEA data in the year 2020, India comes under a lower middle income group of countries, ${ }^{17,18}$ and therefore the affordability of treatment cost of IMRT is beyond the reach of a huge population of India as reported by Chauhan et al ${ }^{13,14}$ and Nair et al..$^{19}$ Most of $\mathrm{H} \& \mathrm{~N}$

Table 3 Comparative combined data of 30 institutions from government and private sectors

\begin{tabular}{|l|l|l|l|}
\hline \multirow{2}{*}{ S. no. } & \multicolumn{3}{|c|}{ Percentage average of head and neck cases } \\
\cline { 2 - 4 } & Total & $\begin{array}{l}\text { Treated with a combination of } \\
\text { photon and electron beams }\end{array}$ & Treated with IMRT/VMAT \\
\hline Total institutes (30) & 39.2 (SD: 14.22) & 16.63 (SD: 20.83) & 24.73 (SD: 37.41) \\
\hline $\begin{array}{l}\text { Government } \\
\text { institutes (16) }\end{array}$ & 38.39 (SD: 14.11) & 22.19 (SD: 11.24) & 79.09 (SD: 26.75$)$ \\
\hline Private institutes (14) & 40.14 (SD: 14.11) & 10.29 (SD: 11.24) & (S) \\
\hline
\end{tabular}

Abbreviations: IMRT, intensity-modulated radiotherapy; SD, standard deviation; VMAT, volumetric modulated arc therapy. 
cancers patients come to the clinic at the advanced stage of the disease due to late screening or no screening facility in the majority of remote areas of India.

\section{Limitations}

Our study has certain limitations such as small sample size, no data on workload of each institute, no case-specific data of electron and photon beam combination in H\&N RT, and no details of equipment in the participating institutes.

\section{Conclusion}

The use of electron beams in combination with photon beams is practiced in most of the government institutions in India for H\&N cancer treatment. However, it is less prevalent in private hospitals because a majority of such cancer centers are treating H\&N cases by IMRT. In the government-run RT centers, even the ones with IMRT facilities, and the use of the latter is less prevalent. As per this study, we conclude that despite the availability of IMRT facility, the combination of electron and photon beam is still relevant in India. Since a large proportion of the patients are still treated with electron beam boost to posterior neck nodes, it is imperative that further studies be conducted to ensure the accurate dosimetry at the photon field-electron field junction.

\section{Conflict of Interest}

None declared.

\section{References}

1 Van Gestel D, Gregoire V, Vermorken JB. Technologic advances in external beam radiotherapy for head and neck cancer. Oncol Hematol Rev (US) 2013;9(2):109-114

2 Kumar R, Sharma SD, Phurailatpam RD, Deshpande DD, Kannan S. Performance characteristics of indigenously developed Bhabhatron-I telecobalt unit. J Med Phys 2005;30:41-47

3 Jethwa AR, Khariwala SS. Tobacco-related carcinogenesis in head and neck cancer. Cancer Metastasis Rev 2017;36(3): 411-423

4 Siddiqi K, Shah S, Abbas SM, et al. Global burden of disease due to smokeless tobacco consumption in adults: analysis of data from 113 countries. BMC Med 2015;13:194

5 Tata Memorial Centre. Evidence Based Management Cancers in India (Three Parts): Guidelines for Modern Radiation Oncology
Practice (Part A). Available at: https://tmc.gov.in/tmh/PDF/ Modern\%20Radiation_EBM_Printing_18\%20Feb.pdf

6 Kemikler G. Dosimetric effects of matching 6 MV photon and electron fields in the treatment of head and neck cancers. Radiat Meas 2006;41(2):183-188

7 Mendenhall WM, Hinerman RW, Amdur RJ, et al. Postoperative radiotherapy for squamous cell carcinoma of the head and neck. Clin Med Res 2006;4(3):200-208

8 Vergeer MR, Doornaert PAH, de Bree R, Leemans CR, Slotman BJ, Langendijk JA. Postoperative elective nodal irradiation for squamous cell carcinoma of the head and neck: outcome and prognostic factors for regional recurrence. Ann Oncol 2011;22(11):2489-2494

9 Bhide SA, Kazi R, Newbold K, Harrington KJ, Nutting CM. The role of intensity-modulated radiotherapy in head and neck cancer. Indian J Cancer 2010;47(3):267-273

10 Gupta T, Kannan S, Ghosh-Laskar S. Agarwal JP. Systematic review and meta-analyses of intense-modulated radiation therapy versus conventional two-dimensional and/or or three-dimensional radiotherapy in curative-intent management of head and neck squamous cell carcinoma. PLoS One 2018; 13(7):1-15

11 Nelms BE, Tomé WA, Robinson G, Wheeler J. Variations in the contouring of organs at risk: test case from a patient with oropharyngeal cancer. Int J Radiat Oncol Biol Phys 2012; 82(1):368-378

12 Van Gestel D, Dragan T, Grégoire V, Evans M, Budach V. Radiotherapy quality assurance for head and neck squamous cell carcinoma. Front Oncol 2020;10:282

13 Chauhan AS, Prinja S, Ghoshal S, Verma R. Cost effectiveness of intensity modulated radiotherapy (IMRT) versus conventional radiotherapy for the treatment of head and neck cancers in India: a study protocol. 2018. Available at: https:// dx.doi.org/10.17504/protocols.io.jzvcp66. Accessed October 22, 2020

14 Chauhan AS, Prinja S, Ghoshal S, Verma R, Oinam AS. Cost of treatment for head and neck cancer in India. PLoS One 2018; 13(1):e0191132

15 Ravichandran R. Has the time come for doing away with Cobalt-60 teletherapy for cancer treatments. J Med Phys 2009; 34(2):63-65

16 Jayarajan K, Kar DC, Sahu R, Radke MG, Singh M. BARC develops cobalt-60 teletherapy machine for cancer treatment. http:// www.barc.gov.in/publications/nl/2005/200502-2.pdf

17 World Bank. World Bank Country and Lending Groups. 2020. Available at: https://datahelpdesk.worldbank.org/knowledgebase/articles/906519-world-bank-country-and-lendinggroups. Accessed October 22, 2020

18 International Atomic Energy Agency. DIRAC (DIrectory of RAdiotherapy Centres).2020. Available at: https://dirac.iaea.org. Accessed October 22, 2020

19 Nair KS, Raj S, Tiwari VK, Piang LK. Cost of treatment for cancer: experiences of patients in public hospitals in India. Asian Pac J Cancer Prev 2013;14(9):5049-5054 